\title{
Blood Products Distribution Center
}

National Cancer Institute

\section{Source}

National Cancer Institute. Blood Products Distribution Center. NCI Thesaurus. Code C133303.

A facility that stores blood or blood products for transfusion under specific controlled conditions prior to shipping it to the final user. 